\title{
Towards Scalable and Sustainable Active Learning in a Large Engineering Department
}

\author{
Jen Rathlin ${ }^{1}$, Eugene $\mathrm{Li}^{1}$, and Andrew Trivett ${ }^{2}$ \\ ${ }^{1}$ Department of Mechanical and Mechatronics Engineering, University of Waterloo; ${ }^{2}$ School of Sustainable Design \\ Engineering, University of Prince Edward Island \\ jen.rathlin@uwaterloo.ca, eugene.li@uwaterloo.ca, and atrivett@upei.ca
}

\begin{abstract}
Students entering undergraduate engineering programs lack the formative experiences of their precursors and are demanding more hands-on, practical, and engaging experiences as part of their education [1]. Starting in 2013, the University of Waterloo engaged in a pilot project to address these needs and to improve the student experience. This paper will discuss the challenges encountered in the establishment of the MME Clinic initiative, the implementation methods used to address these challenges, and lessons learned through the first four years of this project.
\end{abstract}

Keywords: active learning, engineering clinic, design concepts, large class size, hands-on activity, studentdriven

\section{INTRODUCTION}

University engineering departments are challenged by the changing representation of students entering undergraduate programs today, many of whom have not had access to the formative hands-on experiences that were once common in secondary schools[1]. By providing formative experiences through the integration of more experiential active learning components into the curriculum, students can utilize these experiences as they engage with Kolb's experiential learning cycle and practice deeper learning[2].

In 2012, the University of Waterloo Mechanical and Mechatronics Engineering (MME) department sought to address the lack of formative hands-on experiences by proposing a "practicum focused 'student learning environment' aimed at enhancing deeper learning, meaning and connection of theoretical concepts to practical application" as part of a faculty-wide strategic planning exercise[3]. In the initial stages, it was imagined as a pilot program for a faculty-wide effort "to integrate and deepen student learning" and "improve the engagement, retention and overall experience of our undergraduate students"[3].

Through exit surveys conducted from 2010 to 2013, graduating MME undergraduate students identified that opportunities for hands-on experiences were lacking in their programs, and expressed a desire for a more balanced approach to theoretical and practical components of their education[1].

The MME Clinic initiative began in 2013 in response to the educational challenges posed by our students' diverse experiences. The realization of this concept was modelled after similar engineering clinic and design studio concepts developed by other engineering programs, and modified to support the particular context of MME undergraduate programs. However, providing hands-on activities and authentic engineering experiences in a scalable and sustainable format in a large department can be a challenge.

This paper will focus on the integration of these activities in a large department setting, the challenges encountered, and the lessons learned during the project pilot.

\section{BACKGROUND}

The University of Waterloo MME department hosts two large undergraduate programs (Mechanical Engineering and Mechatronics Engineering), with integrated co-operative education programs, featuring two staggered cohorts of students in each program. Class sizes in both programs ranged from 80 to 130 students. Table 1 shows the number of students registered in each program as well as the total number of undergraduate students supported by the MME department from 2013 to 2016.

Table 2 shows the numbers of support personnel available through the MME department for these programs. Over 100 undergraduate courses are offered in the ME and MTE programs. Most faculty members participate in teaching these courses. However, only 3 technical staff members were devoted to undergraduate teaching support at during this period. The other 19 technical staff members were assigned to research projects. While some research technical staff members assisted with undergraduate teaching support when research schedules permitted, undergraduate teaching support was not part of their regular duties and was done on a volunteer basis. 
Table 1: Annual registration in Mechanical Engineering (ME) and Mechatronics Engineering (MTE) undergraduate programs.

\begin{tabular}{|c|c|c|c|}
\hline Academic Year & $\begin{array}{c}\text { ME } \\
\text { students }\end{array}$ & $\begin{array}{c}\text { MTE } \\
\text { students }\end{array}$ & Total \\
\hline $2012-2013$ & 928 & 596 & 1,524 \\
\hline $2013-2014$ & 985 & 629 & 1,614 \\
\hline $2014-2015$ & 993 & 691 & 1,684 \\
\hline $2015-2016$ & 1,024 & 743 & 1,767 \\
\hline
\end{tabular}

Table 2: Program support for ME and MTE undergraduate programs from 2013 to 2016.

\begin{tabular}{|l|c|}
\hline \multicolumn{1}{|c|}{ Support type } & Number \\
\hline Faculty: professors and lecturers & 67 \\
\hline Administrative staff & 14 \\
\hline Technical staff & 22 \\
\hline
\end{tabular}

Prior to the formal start of the MME Clinic initiative, several hands-on activities had been trialed and integrated into ME and MTE curricula. For example, the keychain activity developed by James Baleshta[1] and the engine dissection activity[4] developed by Sanjeev Bedi. These activities received positive feedback from students and whetted the appetites of both students and faculty for more authentic and integrated activities. However, many courses in the ME and MTE curricula are delivered in a traditional format with lectures and tutorials scheduled in 1-hour blocks distributed throughout each day.

\section{MME CLINIC DEVELOPMENT}

\subsection{Program development}

The MME Clinic initiative was seeded with a total of $\$ 240,000$ over four financial years (FY2012/13 to FY2015/16) from the Faculty of Engineering to support purchase of equipment and program development for the Engineering Clinic pilot[3].

In late 2013, a faculty member and a technical staff member were hired to lead and support the initiative. To address the challenges of launching such an ambitious pilot project, department stakeholders were consulted in a series of meetings and interviews to develop a vision statement and to identify challenges and concerns. Department stakeholders included faculty, staff, and current undergraduate students. Tools used to solicit feedback and suggestions included:

- Institutional exit surveys and strategy documents

- Department presentations

- Informal faculty and staff surveys, interviews, and workshops

- Individual conversations

- Student focus groups
- Classroom observations

A working definition was developed to reflect the interpretations and passions of these stakeholders: "The [MME] Clinic inspires better student learning through authentic activities including hands-on, practical applications and engagement with the community in a space where students can experience integration between topics, courses, and programs"[5].

The accompanying vision statement included a broad concept for an integrated and inter-disciplinary studentdriven initiative, in a space modelled after similar engineering clinic and design studio concepts developed by CDIO framework-based spaces, such as the Massachusetts Institute of Technology Centre for Bits and Atoms, as well as makerspaces and other FabLabs. The statement also included discussion on collaboration with community and industrial partners, and a commitment to program assessment.

Challenges and concerns regarding the MME Clinic initiative identified by department stakeholders included:

- Increased workload for collaborating faculty and support staff

- Increased workload for students

- Lack of buy-in from faculty or support staff

- Lack of distinction from traditional lab activities Additional concerns identified by department stakeholders included:

- Toxic department and program cultures

- Negative student experiences

To address stakeholder concerns, a modular approach to concrete and authentic activities was developed with a focus on simultaneously providing low student-to-support staff ratios, low overall demand on support staff, and a low barrier-to-entry model for collaborating faculty. Lower student-to-support staff ratios may contribute to improved student experiences and department culture by allowing students and support staff to connect and build relationships as they engage in activities together.

\subsection{Activity development}

As a result of stakeholder consultation, MME Clinic activities were conceptualized as a cohesive scaffold of experiences targeted at reinforcing and integrating concepts in core courses during the first 6 academic terms of both ME and MTE undergraduate programs. The intention of focusing on core courses during the first 6 academic terms was to achieve the broadest impact and to support students in their development in preparation for a capstone design project experience in their final year of study. Existing hands-on activities were incorporated into the initiative and provided with on-going support.

Activities are varied in topic, scope, and depth, but commonly characterized by the hands-on activities and 
authentic engineering experiences valued by mechanical and mechatronics engineering students. The engineering design process was used as a framework for the development of activities.

The foci of activities were tailored to suit the skills, abilities, and interests of students in each academic term, as well as the learning outcomes and concepts of their courses. For example, activities developed for students in their first academic term focused on building hands-on skills and competence with basic engineering tools, fostering curiosity through exploration of engineering artifacts, and practicing the engineering design process by designing and building small projects (Fig. 1). To contrast, students in their fifth academic term were encouraged to reinforce curriculum content by analysing engineering artifacts and phenomena, and to practice problem investigation and analysis through design iteration of engineering artifacts based on their analyses (Fig. 2).

Activities were developed for small groups of 30 or fewer students supported by 1 technical staff member and a few teaching assistants or co-op students. These numbers ensured low student-to-support staff ratios and low demand on research-focused technical staff.

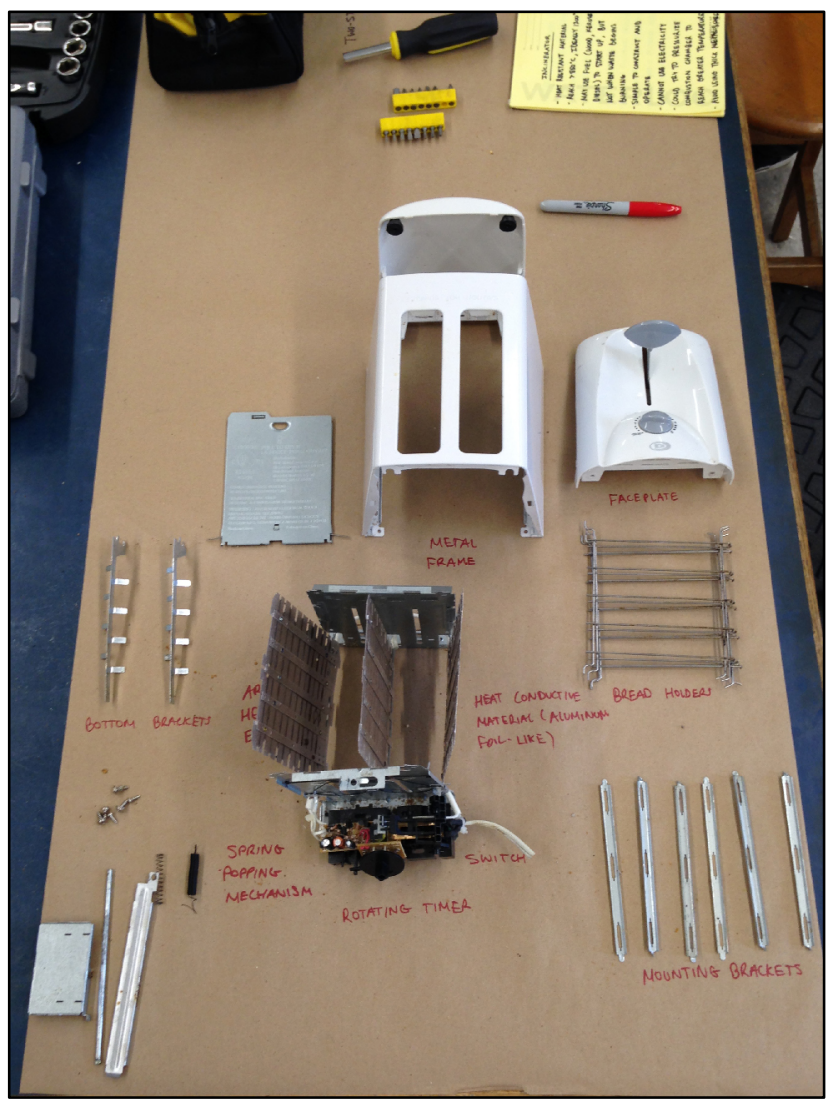

Figure 1: A toaster disassembled as part of an exploration activity in a first-year ME cornerstone course.

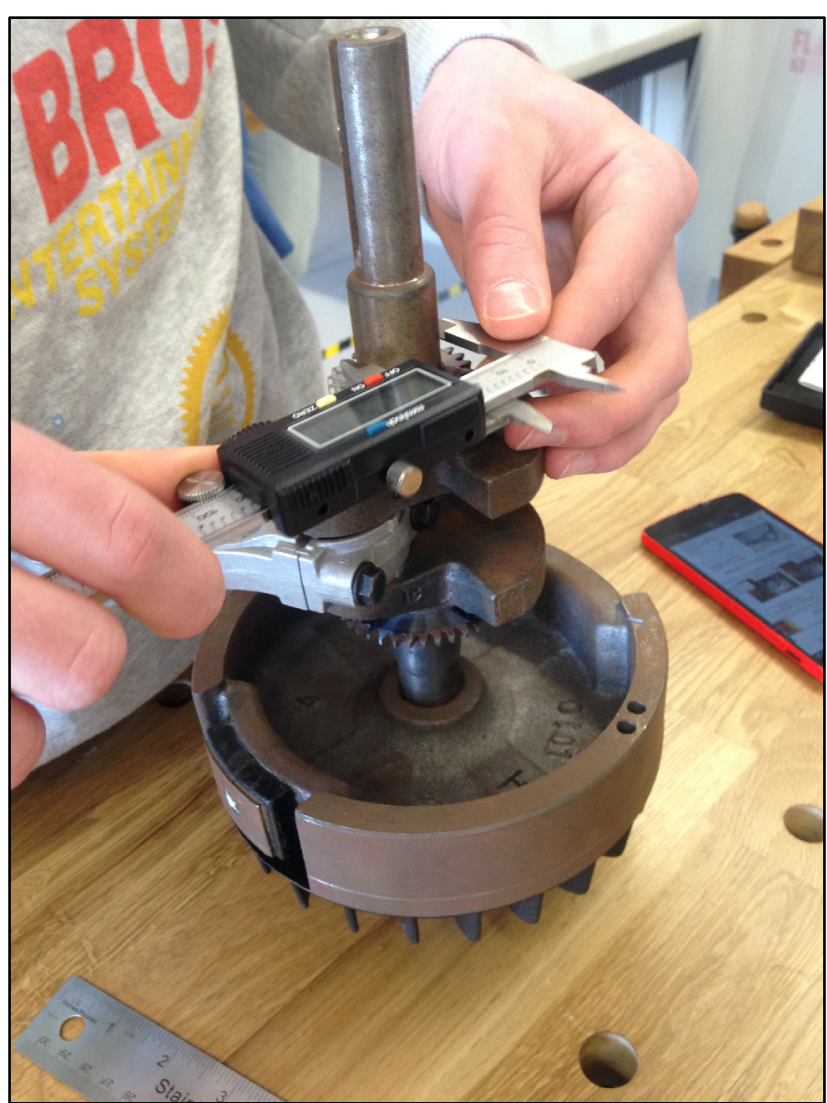

Figure 2: A student measuring a crankshaft from a small engine as part of an analysis and modeling activity in a third-year ME course on the kinematics and dynamics of machines.

Each activity was offered multiple times, scheduled around each cohort's lectures, tutorials, and other weekly scheduled academic events. Students were allowed to choose which session to attend to suit their schedules and preferences.

Modular equipment kits were created for each activity to expedite activity preparations, and to facilitate organization and storage.

\subsection{Space development}

In 2014, two adjacent former chemistry lab spaces (195 sq. m.) on an upper floor of an older engineering building were assigned to the project (Fig. A1). Initial equipment purchases to support development of a makerspace were made at this time, including 8 fused deposition modeling (FDM) 3D printers, 1 stereolithography (SLA) 3D printer, 1 laser cutter, and 12 sets of various hand tools.

In 2015, renovations were planned for the space to be completed in 2016 (Fig. A3). During the renovation period, a nearby chemistry lab space (190 sq. m.) was used temporarily (Fig. A2). Most activities were delivered in these spaces throughout the renovations. Additional 
equipment acquisitions in 2016 include 2 desktop CNC milling machines and an injection moulding demonstration machine.

\section{RESULTS AND DISCUSSION}

Given the scope of the MME Clinic project, it is no surprise that it was met with both challenges and successes over its first four years. During this time, several lessons were learned, including the importance of being open to pivoting, which will be discussed later in this section. During the first four years of this project, numerous challenges and successes were encountered, both large and small. However, this paper will only discuss several major challenges and highlight a few notable successes.

\subsection{Challenges}

One of the main challenges of any pilot project is the need to create a roadmap for the greater project. For this purpose, it is important to be able to measure success in the pilot project. Consequently, the most significant challenge encountered by the MME Clinic initiative was the establishment of metrics and a roadmap for success. Despite intentions stated in the vision statement, metrics for program assessment and program milestones were not clearly identified. As a result, quantifying program impact lacks context because achievement thresholds were never defined.

Another challenge encountered by the MME Clinic initiative was initial reluctance amongst course instructors to implement the activities. Due to the novelty of the approach, some course instructors were hesitant to expose students to unproven and untested MME Clinic activities because there was little demonstrated evidence available on how these experiences might contribute to student learning. In addition, some course instructors were concerned about how new activities might be received by students expecting traditional content delivery methods. However, the value of these activities to the faculty and student experience became clearer as early collaborators integrated these activities into their courses,. Thanks to these early collaborators, course instructor resistance has lessened over time. Also, stakeholder consultation early in program development allowed this resistance to be anticipated and mitigated by focusing activity development on approaches that presented low barriers to entry to both faculty and students. An example of a low barrier-to-entry approach is a short and engaging activity that fits into student schedules and also into established course plans.

As a result of the reluctance demonstrated by some course instructors, the MME Clinic team collaborated with any instructor interested in the potential of these activities. Consequently, the courses that featured MME
Clinic activities were not purposefully selected and a cohesive program of student experiences could not be constructed. As more and more courses experiment with the addition of these activities, it will be increasingly possible to integrate these activities into a coherent and cohesive scaffold. However, at this time, integration between courses is still a challenge.

The final challenge faced was the development of a student-driven makerspace in a relatively small, lowvisibility space. Unlike flagship makerspace initiatives at other universities, the MME Clinic space is comparatively smaller[6] for the size of the student population served and it is not located in a high traffic area nor a central location. As a result, student awareness of the facility is largely limited to those who have been assigned to attend a course activity in the space. And even among students who have participated in an activity, some of these students remain unaware of the potential of the makerspace.

\subsection{Successes}

That is not to say that the MME Clinic initiative has not been a success. Table 3 shows the number of activities developed and delivered from 2013 to 2016. As a result of these efforts, 16 of 18 cohorts of active students enrolled in MME programs in the Fall term of 2016 have experienced at least $1 \mathrm{MME}$ Clinic activity.

On the whole, students have responded to these activities positively and have requested the integration of similar activities in more courses. These activities gave students and teaching staff opportunities to engage in conversations that establish rapport and build relationships. Students were observed using the activities or the makerspace environment as a conversational opening to ask questions about personal and professional interests, experiences, and projects of other students, teaching assistants, staff, and faculty.

Table 3: MME Clinic activity development and delivery.

\begin{tabular}{|c|c|c|c|}
\hline $\begin{array}{c}\text { Academic } \\
\text { Year }\end{array}$ & $\begin{array}{c}\text { Activities } \\
\text { Developed }\end{array}$ & $\begin{array}{c}\text { Activities } \\
\text { Delivered }\end{array}$ & $\begin{array}{c}\text { Courses } \\
\text { Impacted }\end{array}$ \\
\hline $2013-2014$ & 7 & - & - \\
\hline $2014-2015$ & 10 & 20 & 7 \\
\hline $2015-2016$ & 5 & 27 & 12 \\
\hline
\end{tabular}

However, the greatest success of the MME Clinic initiative has been its ability to transform a space focused on serving institutional needs to one that serves students' needs, allowing them to grow as engineers, and helping them learn in ways that can be difficult to teach in a classroom setting. Students have been able to grow their skills in dealing with conflicts constructively, teamwork, and learning who they are as engineers. 
The MME Clinic project has attained these achievements by being sensitive to student needs and listening to student suggestions. Student suggestions have helped the makerspace to mature and have resulted in many large and small changes, including:

- Equipment and supplies choices and availability

- Equipment booking system

- Facebook page

- Logging and payment system for material use

- Online equipment training system

Students have shown great enthusiasm for the makerspace as demonstrated by their use of makerspace equipment, as shown in Table 4, 5, and 6. Many of these students learned about the availability of the makerspace and its resources after a formal introduction through a course activity or project. However, as shown in Table 7 , students return to the makerspace to work on extracurricular and personal projects in their own time, which suggests that the resources satisfy a student need and that students have positive experiences in the space.

Table 4: Bookings of MME Clinic makerspace equipment during the 2015-2016 academic year.

\begin{tabular}{|c|c|c|c|}
\hline Equipment & Fall Term & $\begin{array}{c}\text { Winter } \\
\text { Term }\end{array}$ & $\begin{array}{c}\text { Spring } \\
\text { Term }\end{array}$ \\
\hline $\begin{array}{c}\text { FDM 3D } \\
\text { printer }\end{array}$ & 155 & 458 & 173 \\
\hline $\begin{array}{c}\text { SLS 3D } \\
\text { printer }\end{array}$ & 12 & 30 & 9 \\
\hline Laser cutter & 168 & 307 & 192 \\
\hline Total & 335 & 795 & 374 \\
\hline
\end{tabular}

Table 5: Use in hours of MME Clinic makerspace equipment during the 2015-2016 academic year.

\begin{tabular}{|c|r|r|r|}
\hline Equipment & Fall Term & \multicolumn{1}{c|}{$\begin{array}{c}\text { Winter } \\
\text { Term }\end{array}$} & \multicolumn{1}{c|}{$\begin{array}{c}\text { Spring } \\
\text { Term }\end{array}$} \\
\hline $\begin{array}{c}\text { FDM 3D } \\
\text { printer }\end{array}$ & 324.5 & $1,122.5$ & 553.0 \\
\hline $\begin{array}{c}\text { SLS 3D } \\
\text { printer }\end{array}$ & 35.5 & 96.5 & 17.5 \\
\hline Laser cutter & 189.0 & 130.0 & 209.0 \\
\hline Total & 549.0 & $1,349.0$ & 779.5 \\
\hline
\end{tabular}

Table 6: Quantity of users of MME Clinic makerspace equipment during the 2015-2016 academic year.

\begin{tabular}{|c|c|c|c|}
\hline Equipment & Fall Term & $\begin{array}{c}\text { Winter } \\
\text { Term }\end{array}$ & $\begin{array}{c}\text { Spring } \\
\text { Term }\end{array}$ \\
\hline $\begin{array}{c}\text { ME } \\
\text { undergraduate }\end{array}$ & 65 & 113 & 76 \\
\hline $\begin{array}{c}\text { MTE } \\
\text { undergraduate }\end{array}$ & 50 & 77 & 18 \\
\hline Other & 10 & 14 & 13 \\
\hline Total & 125 & 204 & 107 \\
\hline
\end{tabular}

Table 7: Purpose of MME Clinic makerspace equipment bookings during the 2015-2016 academic year in percentage of total use.

\begin{tabular}{|c|c|c|c|}
\hline Purpose & Fall Term & $\begin{array}{c}\text { Winter } \\
\text { Term }\end{array}$ & $\begin{array}{c}\text { Spring } \\
\text { Term }\end{array}$ \\
\hline Training & $18 \%$ & $12 \%$ & $9 \%$ \\
\hline $\begin{array}{c}\text { Course } \\
\text { project }\end{array}$ & $39 \%$ & $52 \%$ & $43 \%$ \\
\hline Design team & $13 \%$ & $11 \%$ & $11 \%$ \\
\hline Own project & $18 \%$ & $13 \%$ & $29 \%$ \\
\hline Research & $3 \%$ & $7 \%$ & $4 \%$ \\
\hline Other & $10 \%$ & $4 \%$ & $5 \%$ \\
\hline
\end{tabular}

Unfortunately, due to the lack of metrics for success discussed earlier, it is difficult to quantify the impact of the MME Clinic initiative in accordance with established standards, such as graduate attributes. However, it is clear from the feedback received from students using the space that the MME Clinic has developed a robust community of students who are using the space to achieve their learning and personal development goals. For example, upper-year students often comment that they wish that they had more exposure to facilities like the MME Clinic makerspace earlier on in their academic careers. Additionally, incoming students have identified that the presence of the makerspace and the outreach activities facilitated in the space have influenced their decision to attend the University of Waterloo.

\subsection{Future developments}

As identified earlier, metrics for program assessment and program milestones would be useful in evaluating the success of the MME Clinic initiative. Moving forward, we intend to rigorously study the impact of the MME Clinic initiative on graduate attributes, identified learning outcomes, student experience, and other student development goals.

Also, as more activities are developed and integrated into ME and MTE courses, we hope to foster a community of collaborating faculty members committed to the initiative's goals to allow activities to be integrated into a scaffold of student experiences reinforcing the $\mathrm{ME}$ and MTE programs.

Finally, the MME Clinic makerspace will seek to engage in collaborations with other makerspaces and prototyping resources on campus to develop an innovation ecosystem focused on supporting student development and positive student experiences. Similar ecosystems at American post-secondary institutions have been credited with important contributions to campus culture[6]. 


\section{CONCLUSIONS}

In the first four years of the MME Clinic initiative, an approach to activity development suitable for a large engineering department was developed, which has been received positively and continues to attract collaborators. As well, a makerspace with a robust community and strong student acceptance was built. Stakeholder consultation allowed some challenges to be addressed early on in the development of the initiative.

However, due to other challenges encountered, it has been difficult to quantify the impact of MME Clinic activities or the associated makerspace. There is some evidence to indicate that these efforts were successful, but these indicators must be verified rigorously and success must be clearly defined before conclusions can be drawn.

The next phase of this project will focus on program assessment, activity integration between courses, and campus collaborations to strengthen the MME Clinic initiative with an eye to on-going sustainability and success.

\section{Acknowledgements}

The authors would like to acknowledge the contributions made by Jim Baleshta, Roydon Fraser, Andrew Milne, Mike Stachowsky, and Pete Teertstra as well as the co-op students who contributed to the development of the MME Clinic. Jen Rathlin would also like to acknowledge Islai Rathlin for their love, support, and interdisciplinary perspective throughout this project.

\section{References}

[1] James Baleshta, "Increasing Student Practical Experience with the Hurdle of Large Class Sizes," in Proc. CEEA Canadian Engineering Education Conf., CEEA14, (Canmore, AB; 8-11 June), 7 pp., 2014.

[2] Brenda L. Gleason, Michael J. Peeters, Beth H. ResmanTargoff, Samantha Karr, Sarah McBane, Kristi Kelley, Tyan Thomas, and Tina H. Denetclaw, "An Active-Learning Strategies Primer for Achieving Ability-Based Educational Outcomes," in American Jour. of Pharmaceutical Education 75(9) (2011): 186.

[3] Adel Sedra, Vision 2015 Building on Excellence: Waterloo Engineering Strategic Plan 2011-2015 (report, University of Waterloo, 2012).

[4] Andrew Trivett and Jen Rathlin, "Hands-on Explorations as Background Research for First-Year Design Project," in Proc. CEEA Canadian Engineering Education Conf., CEEA15, (Hamilton, ON; 31 May-3 June), 5 pp., 2015.
[5] Andrew Trivett, "What is the Engineering Clinic?" (presentation, University of Waterloo, 2013).

[6] P. Zachary Ali, Malcolm Cooke, Martin L. Culpepper, Craig R. Forest, Björn Hartmann, Marlo Kohn, and Vincent Wilczynski, "The Value of Campus Collaboration for Higher Education Makerspaces," in Proc. of the 1st International Symposium on Academic Makerspaces, ISAM 2016, (Cambridge, MA; 13-16 November), 15 pp., 2016.

\section{APPENDIX A: MME CLINIC SPACE}

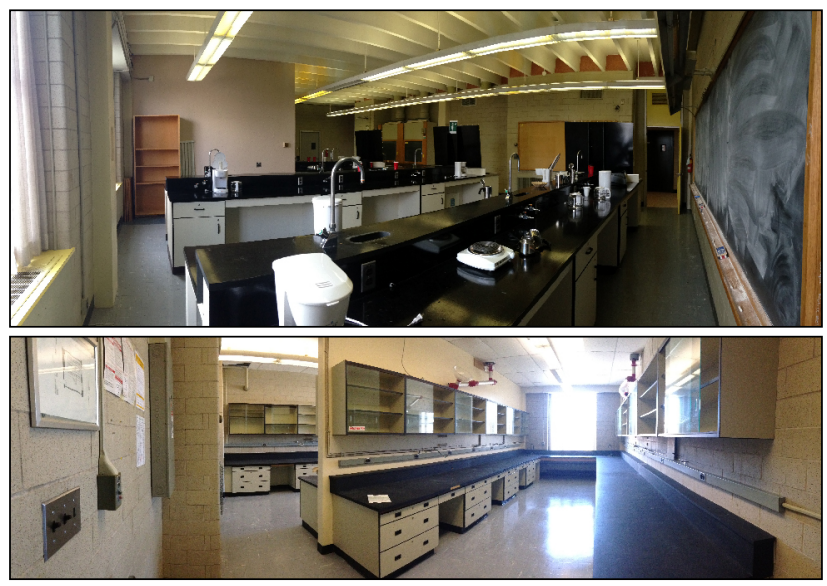

Figure A1: Both lab spaces assigned to MME Clinic before renovations.

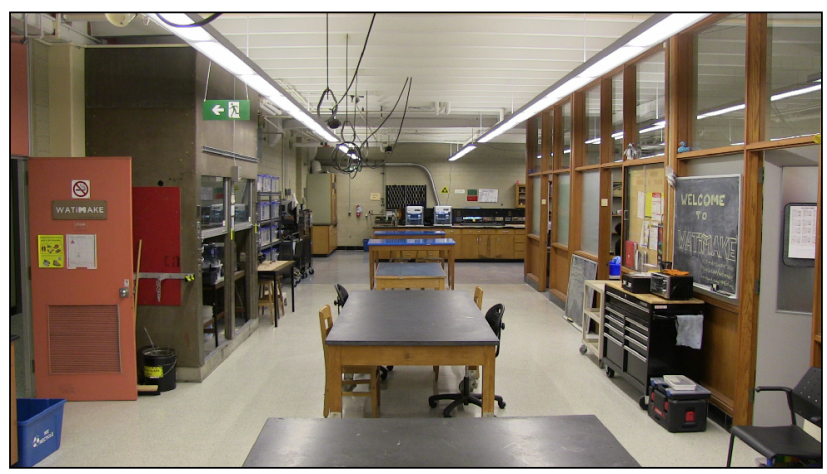

Figure A2: Temporary MME Clinic space during renovations from August 2015 to September 2016.

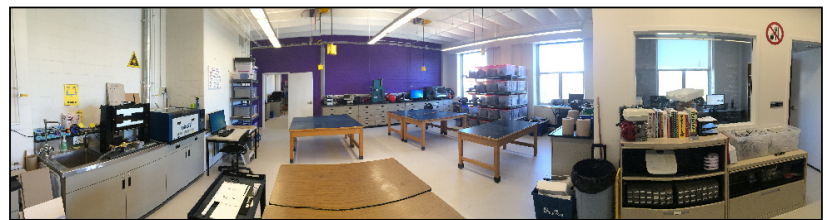

Figure A3: MME Clinic space after renovations completed in September 2016. 